\title{
Interactive effects of silicon and arbuscular mycorrhiza on root growth, uptake of several soil elements, antioxidant potential, and secondary metabolites of Licorice (Glycyrrhiza glabra L.) under water-deficit condition
}

Tahereh Movahhed Haghighi

Mohammad Saharkhiz ( $\nabla$ saharkhiz@shirazu.ac.ir)

Shiraz University https://orcid.org/0000-0003-2151-5006

Mehdi Zarei

\section{Research Article}

Keywords: Claroiedoglomus etunicatum, Drought stress, Glycyrrhizic acid, Licorice, Polyphenols, Silicon

Posted Date: February 9th, 2022

DOI: https://doi.org/10.21203/rs.3.rs-1317111/v1

License: (c) (i) This work is licensed under a Creative Commons Attribution 4.0 International License.

Read Full License 


\section{Abstract}

Aims

Water deficit affect agricultural systems negatively globally. This research objective was to mitigate drought detrimental effects on Licorice growth, utilizing biofertilizer and mineral nutrition. Exogenous application of silicon (Si) and arbuscular mycorrhizal fungi (AMF) may help licorice plant cope with drought stress.

\section{Methods}

An experiment was designed with two Si solute levels in irrigation water (i.e. 0 (Si $\left.\mathrm{S}_{0}\right)$ and $\left.300 \mathrm{mg} / \mathrm{L}\left(\mathrm{Si}_{1}\right)\right)$, two levels of AMF inoculation (i.e. inoculation with Claroiedoglomus etunicatum $\left(\mathrm{F}_{1}\right)$ and without inoculation $\left(F_{0}\right)$ ), and five soil moisture regimes (i.e. 100, 80, 60, 40 and 20\% of field capacity (FC). The impacts of Si and AMF were assessed on licorice yield, mineral uptake, antioxidant potential, and secondary metabolites under water-deficit stress. After two months, the plants were harvested and their morphological traits were measured. Root extracts were utilized for secondary metabolites and nutrient determination.

Results

Under water deficit conditions, there were significant decreases in root length, diameter, and dry weight (DW) $(p<0.05)$, compared to the control. Si and AMF could significantly $(p<0.05)$ enhance root area (47.75-150.64 $\left.\mathrm{cm}^{2}\right)$ under all irrigation levels. Also, Si significantly $(p<0.05)$ increased the level of root colonization in licorice. The maximum glycyrrhizic acid (GA) $(26.62 \mathrm{mg} / \mathrm{g}$ Dw) was achieved by the interaction between Si and AMF in response to 40\% FC. A reduction in total flavonoids and phenolics of licorice was observed under severe drought levels; however, the Si and AMF acted to increase sinapic acid $\left(16.46 \mathrm{mg} / \mathrm{g}_{\mathrm{DW}}\right)$, and trans ferulic acid $\left(1.11 \mathrm{mg} / \mathrm{g}_{\mathrm{DW}}\right)$ in roots. The results indicated that the interaction between Si and AMF positively affected nitrogen $(N)$ and phosphorous $(P)$ concentrations in roots (53.51 and $74.07 \%$, respectively). At low irrigation levels, the concentrations of $P$ and Si elements increased significantly in the roots. Also, there was an increase in potassium concentration (K) in response to 100, 80, and 40\% FC among Si-treated plants (38.5-44.7\%).

\section{Conclusions}

The exogenous application of Si and AMF showed a synergistic impact on the ability to mitigate the adverse effects of drought stress by improving plant growth and enhancing metabolite accumulation in licorice. These findings bring prospective insight into world water deficit crisis conquering.

\section{Introduction}


Licorice (Glycyrrhiza glabra L.) is a medicinal plant from the Fabaceae family. It is a well-known industrial herb, widely utilized in medicine for its therapeutic characteristics because of its broad range of pharmacological actions (Han et al., 2022). Licorice is a key plant resource in arid and semiarid environments for wind protection and sand fixation. Rhizomes of licorice have a large quantity of glycyrrhizic acid, a key bioactive triterpenoid saponin (Heidari et al., 2021; Karkanis et al., 2018). However, careless overexploitation of wild ecotypes of $G$. glabra has recently resulted in a rapid reduction of its populations, if not extinction. Because of the plant's high economic value and the risk of extinction owing to overharvesting, it appears vital to grow and domesticate this valuable species (Zhang et al., 2017). Wild licorice plants are well-suited to growing in challenging situations, including drought, and on lands with nutrient deficiency. These are the two main causes that usually limit licorice production. Glycyrrhiza plants are grown to help restore ecosystems that have been degraded, especially in arid and semi-arid areas (Han et al., 2022). In this regard, plants have evolved a variety of stress-resistance strategies. Plantmicrobe mutualism may influence plant development, nutrient uptake, and resistance to water-deficit stress (Zou et al., 2021). Arbuscular mycorrhizal (AM) fungi can also create a symbiotic relationship with legumes, improving plant mineral nutrition, particularly $N$ and $P$ (Wang et al., 2021). Inoculating plants with $C$. etunicatum (previously Glomus etunicatum) has reportedly induced drought tolerance in various crops, including Vigna radiata (Musyoka et al., 2020), Cinnamomum migao (Liao et al., 2021), and Glycine max Merr. (Igiehon and Babalola, 2021). Mycorrhizal fungi are heterotrophic, meaning that they obtain their carbon content from the plants they live on (Sharma et al., 2020). Mycorrhizal associations are known to promote growth via contribution to intensive $P$ uptake, induction of drought-responsive genes, and activation of different metabolic pathways (Wen-Ya et al., 2021). AMF-colonization can improve the establishment of extensive hyphal networks which assist in water absorption and nutrient uptake, leading to better soil structures (Jajoo and Mathur, 2021). Moreover, among mineral nutrients, Si is widely regarded as a favorable element for plant development because its uptake by plants can promote growth in the face of abiotic stresses (Majumdar and Prakash, 2020). Silicon was reportedly capable of mitigating the negative effects of drought stress on Brassica juncea (Alamri et al., 2020), G. max (Koentjoro et al., 2020), Triticum aestivum L. (Bukhari et al., 2020), and Solanum lycopersicum L. (Chakma et al., 2021). The key mechanisms that support the ability of Si to mitigate the effects of drought stress include ways of enhancing water uptake and transport, regulating stomatal behavior and water loss, as well as accumulating solutes and osmoregulatory substances. The mechanisms also promote the root osmotic driving force, improve root/shoot ratios, regulate aquaporins, increase root hydraulic conductance, enhance mineral nutrient uptake, maintain nutrient balance, and induce plant defense associated with signaling events. These are collectively known to assist plants in maintaining water balance (Rehman et al., 2021; Thakral et al., 2021; Thorne et al., 2021; Wang et al., 2021). In the light of the said cases of research, the goal of the present work was to evaluate how licorice responds to Si and AMF, especially under water-deficit stress. To the best of our knowledge, such information has not been published before. To achieve this aim, licorice plants were treated by five levels of drought stress (i.e. $100,80,60,40$, and $20 \%$ of $\mathrm{FC})$ in the presence or absence of $\mathrm{Si}(300 \mathrm{mg} / \mathrm{L})$ and $C$. etunicatum symbiosis. 


\section{Materials And Methods}

Soil characteristics Soil samples were taken from the upper $(0-30 \mathrm{~cm})$ horizon of the soil profile before being air-dried. They were sieved (via a 2-mm sieve) and blended in appropriate ways. The soil characteristics including texture (Beretta et al., 2014), pH (Bargrizan et al., 2017), electrical conductivity (EC) (Aboukila and Norton, 2017), organic matter (OM) (Miyazawa et al., 2000), cation exchange capacity (CEC) (Meimaroglou and Mouzakis, 2019), the available amount of phosphorus (Shen et al., 2019), total nitrogen quantity (Guebel et al., 1991), potassium content (Kumar and Gill, 2018), and micronutrients' concentrations such as $\mathrm{Zn}, \mathrm{Fe}, \mathrm{Cu}$, and Mn (Lindsay and Norvell, 1978) were determined via referenced methods. The physicochemical characteristics of the soil are presented in Table S1.

\section{Plant material}

This experiment was carried out in the College of Agriculture, Shiraz University. The seeds of G. glabra were collected from Eghlid (Aspas village, $52^{\circ} 23^{\prime} 58^{\prime \prime} \mathrm{E}$ and $30^{\circ} 38^{\prime} 31^{\prime \prime} \mathrm{N}$ ), a region in the north of Fars province, Iran. The seeds were scarified by soaking in concentrated $\mathrm{H}_{2} \mathrm{SO}_{4}$ (97\%-Merck) for 10 min, washed with running water several times, and immediately sown in transplant trays (Peat moss and perlite mix, 2:1). In each cell of the trays, two seeds were sown. They were allowed to grow in the greenhouse after sowing (Day: $27 \pm 1^{\circ} \mathrm{C}$, night: $23 \pm 1^{\circ} \mathrm{C}$, humidity: $70 \pm 3 \%$, light: 40000 Lux). A month after germination, the plantlets were transferred into small plastic pots containing $250 \mathrm{~mL}$ of field soil and sand mixture (2:1) (Lang et al., 2019). Bigger pots (50 cm height $\times 29 \mathrm{~cm}$ diameter) were used for transplanting 6-month-old seedlings in a sandy medium (soil and sand mixture (2:1)) (Lang et al., 2019). Each pot had two seedlings.

\section{Preparation of microbial inoculation}

C. etunicatum was supplied by the soil biology lab at Shiraz University, department of soil science, and was previously separated by Dr. Mehdi Zarei. This fungus was propagated in a sterilized mixture of soil and sand (1:1) for five months using Sorghum bicolor as the host plant. The inoculum potential for infectivity as root colonization was estimated at $85 \%$. A number of 10 spores existed per gram of substrate. The inoculum $(250 \mathrm{~g})$ was added to the root zone before doing the final transplantation. Each mycorrhizal pot was filled with soil containing fungal spores, mycorrhizal roots, and mycelia of $C$. etunicatum. Meanwhile, non-mycorrhizal pots were supplied with an equal amount of washed sand (Zarei et al., 2020).

\section{Experimental design and growth conditions}

A pot experiment was performed in a factorial experiment that was arranged in a completely randomized design with three factors, including five levels of drought stress (i.e. 100 (control), 80, 60, 40 and 20\% of field capacity, represented by $W$ (i.e. $W_{100}$ (control), $W_{80}, W_{60}, W_{40}$, and $W_{20}$ ), two levels of $A M F$, denoted by $F$ (i.e. $\mathrm{F}_{0}$ : without inoculation, $\mathrm{F}_{1}$ : inoculated), and two levels of $\mathrm{Si}$ solute in irrigation water (i.e. $\mathrm{Si}_{0}$ : without $\mathrm{Si}$ application, $\mathrm{Si}_{1}: 300 \mathrm{mg} / \mathrm{L}$ of $\mathrm{SiO}_{2}$ ). Four replications were considered. After two weeks of 
adaptation and plant establishment in pots, irrigation treatments were carried out for two months. Irrigation was performed differently to make the soil reach the five different levels of FC. The weighting approach was used for adjusting the stress treatments (Abbaszadeh et al., 2020). As the plants consumed water and as evaporation occurred, the weight of pots decreased gradually through the course of observations. For each treatment group, the five drought levels were applied. In the case of Si nutrition, $\mathrm{SiO}_{2}$ was dissolved in the irrigation water. Every other day, water was added to the pots after weighing the pots so that the amount of soil moisture could be measured indirectly and the specifications of each treatment could be upheld. After eight weeks, and under the respective conditions of growth, the plants were harvested for analysis.

\section{Parametric measurements}

\section{Morphological parameters}

The plants were entirely removed from the pots at the end of the experiment. After cleaning the roots, various parameters were examined and measured. Root length was measured by a scientific ruler and root diameter was measured by a caliper ( $0.01 \mathrm{~mm}$ accuracy) (Shan et al., 2018). The root fresh weight (FW) was determined promptly after harvesting the plants. Then, the roots were oven-dried at $80^{\circ} \mathrm{C}$ for 24 $\mathrm{h}$ before measuring their dry biomass. Dry and fresh weights of the roots were measured with a four-digit scale (Lamacque et al., 2020). Root volume was calculated according to the volume displacement method (Harrington et al., 1994). Root area was measured by MATLAB software (Jadhav, 2021).

\section{Assessment of AMF colonization}

Fresh root segments ( $2 \mathrm{~cm}$ long) were dyed as described by Rahimi et al., 2021 with minor modifications so that root colonization by AMF could become measurable. Stained root segments were selected randomly for evaluation under the microscope and according to a relevant approach in the literature (Trouvelot et al., 1986). A Nikon Eclipse E200 microscope was used for examining the segments (at 40x magnification). The mycorrhizal inoculation parameters and confirmation were calculated utilizing Mycocalc (http://www2.dijon.inra.fr/mychintec/Mycocalc-prg/MYCOCALC.EXE) (Etemadi et al., 2014).

\section{Glycyrnhiza glabra root extraction and quantitative analysis by HPLC}

The well-ground powder was prepared from the dried roots of each sample (500 mg) and its extract was taken by ethanol: water (70:30). After adding the solvent to the powder and after sonicating them for half an hour in an ultrasonic bath, the extracts were centrifuged and injected into High-Performance Liquid Chromatography (HPLC). Extraction and injection were done in three replicates (Esmaeili et al., 2019).

The glycyrrhizic acid content in the licorice roots was evaluated by Knauer liquid chromatography device consisting of a 2695 Separations Module (Germany), equipped with a $100 \mu \mathrm{l}$ loop and Photodiode Array Detectors (PDA) using a C18 column (Knauer, $25 \mathrm{~cm} \times 4.6 \mathrm{~mm}$ Eurospher 100-5), with water that contained $0.3 \% \mathrm{H}_{3} \mathrm{PO}_{4}$ (solvent $\mathrm{A}$ ) and acetonitrile (solvent $\mathrm{B}$ ) as the mobile phase. The flow rate was 1 
$\mathrm{ml} / \mathrm{min}$. The samples were monitored at a wavelength of $250 \mathrm{~nm}$ in the case of glycyrrhizic acid (Esmaeili et al., 2019).

\section{Antioxidant activity and $50 \%$ inhibition (IC-50) determination}

Total antioxidant activity was calculated according to the protocol of Taban et al., 2021. The absorbance was read at $517 \mathrm{~nm}$ (Taban et al., 2021). According to the DPPH free-radical scavenging method, the sample concentration was assessed in relation to IC-50 (Half maximal Inhibitory Concentration). The inhibition (\%) was plotted against sample concentrations and each test was performed three times (Taban et al., 2018).

\section{Determination of total phenols and flavonoids}

The total phenolic quantity of the ethanolic extracts was assessed by the method described by Haghighi and Saharkhiz, 2021. The absorbance read by a spectrophotometer at $750 \mathrm{~nm}$ (Epoch Biotek, Winooski, VT, USA). The absorbance of ethanolic extracts to estimate the concentration of total flavonoids done by the method described by Taban et al., 2020. The absorbance was measured at $510 \mathrm{~nm}$ by a microplate reader in the spectrophotometer (Taban et al., 2020).

\section{Extraction and profile assay of polyphenolic compounds by HPLC}

The extraction was carried out using a solvent ( $85 \%$ methanol/15\% acetic acid) with a concentration with the method described by Gholami et al., 2018 with little modifications. The polyphenols were collected using a syringe that had a filter on its head $(0.45 \mu \mathrm{m})$. Then, they were transferred to glass containers and remained frozen until HPLC analysis (Gholami et al., 2018).

Polyphenolic components in G. glabra extracts were separated, identified, and quantified by HPLC analysis on an Agilent 1200 series (USA), equipped with a reverse-phase Zorbax Eclipse (XDB)-C18 column (10 cm $\times 5 \mathrm{~mm}$ i.d.; $150 \mathrm{~mm}$ film thickness) and with the assistance of a photodiode array detector (PAD). The method completely described by (Mousavi et al., 2021).

\section{Mineralogical analysis by X-ray Diffraction}

The root powder ash $(1 \mathrm{~g})$ of each sample was prepared at $500^{\circ} \mathrm{C}$ and then became subjected to X-ray powder diffraction (XRD) analysis. The quantity of $\mathrm{N}, \mathrm{K}, \mathrm{P}$, and $\mathrm{Si}$ in the samples was measured by $\mathrm{X}$-ray diffraction (XRD) (Bruker's X-ray Diffraction Model: D8 Advance; Germany) while Cu Ka radiation had a wavelength of $1.54 \AA$ in the three replicates. The relative abundance of minerals was measured using peak height intensity as an indication. Scanning was carried out from 15 to $75^{\circ} 2 \theta$, with a step interval of $0.05^{\circ}$ and with a counting time of $1 \mathrm{~s}$ per step. Quantitative analysis of mineral abundance was carried out using the X'Pert HighScore software (Oliveira et al., 2012).

\section{Statistical Analysis}


This research mostly involved a pot experiment in a factorial arrangement with four replications in a completely randomized design. It had three factors, i.e. drought, AMF, and Si. A general linear model was employed for statistical analysis and for dealing with the entire experimental data using Minitab software (version 17). Statistical significance was defined at $p<0.05$ (Tukey's test). In the case of significant interactions, the slice method was applied to obtain mean comparisons. Principal component analysis was also used according to a correlation matrix by Minitab software. Corrplot was drawn by R software version 4.1.1 (corrplot package) and path analysis was performed by IBM SPSS (version 27).

\section{Results}

\section{Plant Biomass}

In the present study, the fresh and dry weights of roots were evaluated under experimental treatments. The results showed that lower irrigation levels led to a significant decrease in both types of root weight $(p<0.05)$. It is noteworthy that the effects observed from the three irrigation levels $\left(W_{60}, W_{80}\right.$, and $\left.W_{100}\right)$ were not significantly different from each other $(p<0.05)$. The lowest fresh and dry weights were observed in response to severe drought treatment $\left(\mathrm{W}_{20}\right)$ which brought about a decrease of $67 \%$ compared with the control. While different irrigation levels had a significant $(p<0.05)$ impact on the fresh and dry biomass of licorice rhizomes (Figs. 1A and 1B), Si and fungi did not have significant effects on the root weight.

\section{Root characteristics (length, volume, area, and diameter)}

An analysis of licorice root length showed that the longest roots occurred as a result of the well-irrigated treatment $\left(\mathrm{W}_{100}\right)$, while other treatments showed a significant $(p<0.05)$ reduction in root length, compared to the control $(p<0.05)$. It is noteworthy that no significant difference was observed among other irrigation levels (i.e. $W_{20}, W_{40}, W_{60}$, and $W_{80}$ ) (Fig. $2 A$ ).

In the case of root volume, a decrease in irrigation levels caused the root volume to decrease significantly $(p<0.05)$. In this respect, however, the three irrigation levels $\left(\mathrm{W}_{60}, \mathrm{~W}_{80}\right.$, and $\left.\mathrm{W}_{100}\right)$ were not significantly different from each other. The smallest root volume was observed in response to the severe drought treatment $\left(W_{20}\right)$ which showed a decrease of $64 \%$ compared with the $W_{100}$. While different irrigation levels had a significant $(p<0.05)$ effect on licorice root volume (Fig. 2B), Si and fungi did not have significant effects on this parameter.

According to an analysis of root area (Table S2), maximum root area in well-irrigated treatments was observed as a matter of interaction between $\mathrm{Si}$ and $\mathrm{F}\left(150.64 \mathrm{~cm}^{2}\right)$. In plants of severe drought stress $\left(\mathrm{W}_{40}\right)$, however, Si application per se was the cause of maximum root area $\left(113.36 \mathrm{~cm}^{2}\right)$ (Table S2).

In general, root diameter decreased by a lowered level of irrigation (i.e. severe drought stress). $\mathrm{F}$ and $\mathrm{Si}$ each, per se, maintained the value of root diameter almost akin to the control group under severe drought stress $\left(\mathrm{W}_{20}\right.$ and $\left.\mathrm{W}_{40}\right)$. However, the interaction between $\mathrm{Si}$ and $\mathrm{F}$ in $\mathrm{W}_{20}$ caused a significant decrease in 
root diameter, compared with the control $(p<0.05)$. The highest values were observed by the effect of $\mathrm{W}_{80}$ when using either mycorrhiza (19.45 mm) or Si (18.77 mm) (Table S2).

\section{Mycorrhizal colonization}

Microscopic assessments revealed that non-inoculated plants acquired no or low levels of AMF colonization. $C$. etunicatum successfully colonized the roots of licorice under various treatments. Plants that were inoculated with $C$. etunicatum, and were integrated with $\mathrm{Si}$, showed a significant $(p<0.05)$ increase in root colonization. Specifically, these rates of increase were $3321 \%$ and $1685 \%$ in response to drought stress and well-watered conditions, respectively, compared with the control. Evaluations showed that $\mathrm{W}_{40}$ led to a minimum of root colonization. Meanwhile, $\mathrm{Si}$ application increased the amount of this variable in all irrigated levels, except in the case of $\mathrm{W}_{20}$. Evaluations among inoculated plants showed that $\mathrm{Si}_{0}$ treatments exhibited fewer percentages of root colonization, compared with the $\mathrm{Si}_{1}$ treatment. Observations also revealed that the Si improved root colonization by $11.51 \%$ under severe drought stress, i.e. at $\mathrm{W}_{40}$. In general, $\mathrm{Si}$ had a positive effect on root colonization in all irrigation levels, except at $\mathrm{W}_{20}$ which meant an unrelenting effect of severe drought stress (Fig. 3).

\section{Glycyrrhizic acid}

An analysis of GA in licorice roots showed that the highest amount of this metabolite $(26.62 \mathrm{mg} / \mathrm{g} \mathrm{DW})$ was obtained at $\mathrm{W}_{40}$ by applying integrated $\mathrm{Si}$ and $\mathrm{F}$ (Fig. 4). In well-irrigated treatments, the $\mathrm{Si}$ application alone was able to enhance GA content $\left(18.39 \mathrm{mg} / \mathrm{g}_{\mathrm{DW}}\right)$. Regardless of Si usage, the severe drought level $\left(\mathrm{W}_{40}\right)$ caused mycorrhizal-inoculated plants to show a notable increase in the amount of GA $\left(16.43 \mathrm{mg} / \mathrm{g}_{\mathrm{DW}}\right)$, compared with the same irrigation level in non-mycorrhizal plants (Fig. 4).

\section{Total flavonoid, antioxidant activity, and IC-50}

Total flavonoids in licorice roots were increased significantly by Si and $\mathrm{F}(p<0.05)$. They caused 7.85 and $9.28 \%$ enhancement in the total flavonoid content, respectively (Figs. 5A and 5B). G. glabra root extracts showed an ability to scavenge DPPH free radicals which have been often seen as a measure of total antioxidant activity (Fig. 6). The total antioxidant activity in licorice roots at different levels of irrigation and mycorrhizal inoculation showed that the well-irrigated treatment $\left(W_{100}\right)$ led to the highest antioxidant activity $(60.86 \%)$. In severe drought stress $\left(\mathrm{W}_{20}\right)$, the presence of mycorrhiza ultimately maintained the level of antioxidant activity at $59.65 \%$, although this had no significant difference with the control. Regardless of $\mathrm{Si}$ and F, root extracts of plants in the $80 \% \mathrm{FC}$ irrigation demonstrated a higher ability to scavenge free radicals (IC-50 $=0.73 \mathrm{mg} / \mathrm{ml}$ ) as compared to other irrigation levels. As a matter of $\mathrm{Si}$ and mycorrhizal interaction, severe drought stress $\left(\mathrm{W}_{40}\right)$ induced a higher capacity in plants to scavenge free radicals (IC-50 $=1.63 \mathrm{mg} / \mathrm{ml})$. Si alone was able to keep the IC-50 at a low quantity $(0.95 \mathrm{mg} / \mathrm{ml})$ in response to $W_{80}$, hence its great capacity to scavenge free radicals (Table S3).

\section{Total phenol and polyphenol profile}


The results of total phenol determination showed that Si and F, separately, did not have a significant effect on the amount of total phenol at different drought stress levels. But interactions between mycorrhiza and Si significantly $(p<0.05)$ increased the amount of total phenol in the $\mathrm{W}_{40}$ group $(1.74$ $\mathrm{mg} / \mathrm{g}_{\mathrm{DW}}$ ) compared with other irrigation levels. In plants without Si and mycorrhizal inoculation, no significant difference was observed between the effects of the well-irrigated treatment $\left(\mathrm{W}_{100}\right)$ and those of the severe drought stress $\left(\mathrm{W}_{20}\right.$ and $\left.\mathrm{W}_{40}\right)$ on total phenol content (Table S3).

The HPLC examination of polyphenolic compounds in licorice roots and their profile showed that the highest amount of sinapic acid $\left(10.11 \mathrm{mg} / \mathrm{g}_{\mathrm{DW}}\right)$ occurred in well-irrigated treatments when plants were inoculated with mycorrhiza. In severe drought stress levels $\left(\mathrm{W}_{40}\right)$, however, the combined application of $\mathrm{Si}$ and $\mathrm{F}$ could significantly $(p<0.05)$ increase the amount of sinapic acid $(16.46 \mathrm{mg} / \mathrm{g}$ DW $)$. As the irrigation level decreased, the quercetin content reduced significantly (44.1\%) compared with the well-irrigated treatment $\left(\mathrm{W}_{100}\right)(p<0.05)$. Irrespective of $\mathrm{Si}$ and $\mathrm{F}$, more severe drought stress levels caused a significant increase $(p<0.05)$ in the amount of trans-ferulic acid $(0.74-0.91 \mathrm{mg} / \mathrm{g} \mathrm{DW})$. Nonetheless, Si application on plants of the $W_{100}$ treatment maximized the amount of trans-ferulic acid $\left(1.11 \mathrm{mg} / \mathrm{g}_{\mathrm{DW}}\right)(p<0.05)(\mathrm{Table}$ S4).

\section{Concentration of plant nutrients}

Concentrations of select nutrients were evaluated in licorice roots (Table S5). Regardless of Si and mycorrhiza treatments, the concentration of $\mathrm{K}$ reached a maximum amount in the well-irrigated treatment $\left(\mathrm{W}_{100}\right)$. In plants of the $\mathrm{Si}$ or $\mathrm{F}$ treatments, there was no significant variation in $\mathrm{K}$ amount at various drought stress levels. The amount of $\mathrm{N}$ in inoculated plants, at all irrigation levels, showed a significant increase $(p<0.05)$, compared to non-inoculated plants. Si and $\mathrm{F}$ interactions were able to maximize the $\mathrm{N}$ concentration in plants of the severe drought stress treatment $\left(\mathrm{W}_{20}\right)$. However, Si alone could not significantly increase the $\mathrm{N}$ concentration in response to the severe drought treatment $\left(\mathrm{W}_{20}\right)$. Regardless of $\mathrm{Si}$, the concentrations of $\mathrm{P}$ in inoculated plants were significantly $(p<0.05)$ higher than in noninoculated plants in response to well-irrigated and moderated drought levels $\left(W_{100}, W_{80}\right.$, and $\left.W_{60}\right)$. In the case of $\mathrm{Si}$ and $\mathrm{F}$ interaction, $\mathrm{W}_{80}$ and $\mathrm{W}_{20}$ treatments led to the maximum amount of $\mathrm{P}$. Drought stress had no significant effect on P concentration at $40,60,80$, and $100 \%$ FC, irrespective of AMF and Si treatments (Table S5).

\section{Principal component analysis of the measurable traits of G. glabra in a combination of effects caused by mycorrhiza, silicon, and drought}

In the biplot of PC analysis, the first two PCs represented $46 \%$ of the variation in the measured traits among the treatment groups (Fig. 7). The first PC explained $24 \%$ of the variation and comprised root diameter, root fresh and dry weights, root volume, root area, root length, quercetin, and Si. In contrast, the second PC accounted for $21.9 \%$ of trait-related variations, comprising root colonization, total phenol and flavonoid contents, and nitrogen content. In the bi-plot and PC analyses, the cosine of the angles between 
vectors showed the extent of correlation between traits. In the present study, the projection of treatment groups on the two PCs in the bi-plot showed that the studied treatments were divided into two distinct groups. The first group comprised 12 treatments, i.e. T1, T2, ... and T12 in association with the first PClinked measurements of parameters. Meanwhile, the treatments T13, T14, ... and T20 were categorized into the second group for having a higher association with the second PC-linked traits (Fig. 7).

\section{Correlation and path analysis of measured parameters in G. glabra under a combination of mycorrhiza, silicon, and drought}

Using correlation and path coefficient analysis, there were successful evaluations of the relations among licorice root traits, including root colonization, elemental analysis, and secondary metabolite production (Figs. S1 A and S1 B). Stronger positive correlations were found between root traits. These were, namely, root fresh weight, dry weight, volume, and diameter. Among the secondary metabolites, total phenol and total flavonoids showed a good positive correlation between each other (Fig. S1 A). In comparison with the simple correlation analysis, path analysis was aimed at the dependent and independent traits of licorice. The results demonstrated that sinapic acid and GA maintained the highest direct influence as expressed in $\beta=0.719(p<0.001)$. Also, total phenol and total flavonoids showed a significant direct effect $(p<0.01)$ as expressed in $\beta=0.707$ (Fig. S1 B). In sum, these traits can be improved in their performance through path analysis.

\section{Discussion}

Drought is the most important abiotic stress that limits crop productivity worldwide (Tahmasebi et al., 2019). In the present study, the interaction between Si and AMF inoculation was seen as a mitigation factor against stress, thereby assisting in the maintenance of plant yield, antioxidant potential, and secondary metabolites of G. glabra under water-deficit conditions. According to biomass analysis in the present study, lower amounts of dry and fresh biomass were achieved under reduced irrigation levels. Similarly, previous research indicated how water deficit caused variations in the decrease of fresh and dry biomass in T. aestivum L. (Pour-Aboughadareh et al., 2019) and Tetraena mandavillei L. (Alam et al., 2021). The interaction between Si and mycorrhiza did not cause a substantial difference in licorice biomass production but, contrary to the present study, several studies have shown that Si and mycorrhiza can increase plant biomass in Glycyrrhiza uralensis (Zhang et al., 2020), Arachis hypogaea L. (Patel et al., 2021), and Nicotiana tabacum L. (Begum et al., 2021). This increase in plant biomass supposedly occurs by a higher rate of carbon assimilation and photosynthesis. Previous studies have reported that drought stress can reduce root diameter and root length in Gossypium hirsutum L. (Xiao et al., 2020) and Brassica napus L. (Arifuzzaman and Rahman, 2020), thereby confirming the results of the current work. In legumes and gramineae, mycorrhiza is known to support the growth of root diameter (Liu et al., 2020) which is in agreement with current observations.

Si has reportedly assisted plant growth in G. max Merr. (Hussain et al., 2021) and Phaseolus vulgaris L. (Boshkovski et al., 2020). Specifically, it increased root length and biomass, nodule growth, and improved 
nodule function when supplied into the root medium under drought conditions (Tripathi et al., 2021). According to the current results, root volume was affected and notably reduced in response to severe drought stress only. Using mycorrhiza at moderate drought stress and/or using Si at severe drought levels led to the maximum root area. These variations in root system morphology influenced the function of roots. The characteristics of roots improved in response to Si nutrition and assisted plants in better absorption of water and nutrients. Similarly, applying Si to plants growing in Si-deficient soils may help the absorption of water and nutrients by plants. AM-induced phosphate assimilation usually improves in mycorrhizal plants and contributes to plant development (Liu et al., 2019). AMF helps host-plants partly maintain their rate of development, despite the effects of stress, by regulating a series of signaling pathways between the plant and the fungus, thereby facilitating the photosynthetic rate and other gas exchange-related features (Huang et al., 2020). Inside plant roots and in the soil, AMF can substantially increase the surface area available for nutrient absorption by plants (Gavito et al., 2019; Ma et al., 2021). Therefore, in the case of mycorrhiza and $\mathrm{Si}$, root traits in many cases are frequently bound to improve. Using mycorrhiza and $\mathrm{Si}$, either alone or in combination, can result in a better performance of roots while improving their features despite drought levels. Similar to the current study, root traits and total biomass production of Zea mays L. seedlings were enhanced by Si supplementation in the soil (Ali et al., 2021; Rivero et al., 2018). In the face of drought stress, root function can be largely affected, although specific mechanisms can help regulate the growth and architecture of the root system, while also modifying cell water permeability (Maurel and Nacry, 2020).

In the current study, Si and AMF each had a considerable contribution to the content of licorice roots, especially the flavonoids. Meanwhile, the interaction effect of Si and AMF led to a significant increase in total phenol and sinapic acid content. By modifying secondary metabolism in plants, AMF has the major role of strengthening plant resistance against abiotic stress. As a result, AMF may increase the biosynthesis of polyphenols and flavonoids (Liang et al., 2021). In the scientific literature, researchers indicated that AMF can help produce more amounts of phenols in the shoots when colonized by Ocimum basilicum L., compared to non-colonized plants (Hazzoumi et al., 2015). Similarly, the present study showed that the positive effect of AMF was observed more noticeably in response to $\mathrm{W}_{40}$ which enhanced the total phenol content. The formation of mycorrhizal symbioses between plant roots and commercially-important groups of useful fungi can be seen as one of the most important mechanisms influencing phytochemical biosynthesis (da Cruz et al., 2020). Research on AMF revealed its effectiveness by altering terpenoid metabolism and the shikimate pathway, thereby boosting the biosynthesis of isoprenoids, polyketides, and polyphenols by regulating shikimate pathways (Tahat and Al-Momany, 2021; Verma et al., 2021). Such compounds with high antioxidant potential are known by their mechanisms to enhance plant tolerance against unfavorable drought conditions. This may be one of the causes that led to a lower level of IC-50 because of fungal inoculation in the present study and also in a previous work (Haghighi et al., 2022). Flavonoids from legumes have reportedly helped the growth of vesicular-arbuscular mycorrhizal fungi and promoted the transcription of nodulation genes in symbiotic relationships (Agnolucci et al., 2020; Ramesha et al., 2020). Other studies also found that colonized root cells underwent a variety of cytological and metabolic changes, including changes in the regulation of 
plastid biosynthetic pathways and the Krebs cycle, as well as increases in the production of flavonoids, quercetin, isoprenoids, polyketides, and polyphenols (Mousavi and Karami, 2022). As stated in the current study, trans ferulic acid increased under drought stress, whereas quercetin decreased. It was discovered that water deficit caused an increase in the amount of plant phenolics, primarily ferulic acid. Since drought stress makes the photosynthetic apparatus more sensitive to the radiation it receives, a lack of water in the leaf tissue might trigger defensive mechanisms such as the creation of phenolic compounds (Riaz et al., 2019). These increases in phenolics could suggest that the system which stands against drought tolerance is triggered for the plant to better receive radiation and to restrict the negative impacts on the photosynthetic apparatus at times of stress (Kosobryukhov et al., 2020; Zahedi et al., 2019). During water deficit, phenolics may be important in scavenging reactive oxygen species (ROS) and in relieving oxidative stress during recovery. A reduction in the water potential in leaves causes a rise in total phenolic content, including ferulic acid, which could emanate from protective mechanisms being triggered and could denote a sign of drought resistance (Dias et al., 2021; Sharma et al., 2019).

The findings of the present study showed that maximum GA was achieved by the interaction between $\mathrm{Si}$ and AMF under severe drought stress. Partially, similar to the present findings, a study on G. uralensis also showed that drought stress was able to increase root GA concentration, regardless of the mycorrhizal status. In particular, this increase was significant in the case of non-AMF plants under extreme drought stress (Awan et al., 2021; Zhang et al., 2017). While the major triterpenoid saponin in licorice is GA, its antioxidant activity is expected to play a key role in ROS scavenging, thereby reducing oxidative damage considerably (Harikrishnan et al., 2021). Furthermore, an increase in GA concentrations during drought stress could be associated with a decrease in root biomass. More biosynthesis gene expressions occurred in AMF plants under mild drought stress, implying that the up-regulation of genes for the GA biosynthesis ultimately caused the increase in GA concentrations in drought-stressed AMF plants (Hu et al., 2020; Shao et al., 2019).

In agreement with the current study, which observed that Si application improved several parameters of colonization, the exogenous Si increased the Si content in Cicer arietinum plants and improved the plant potential to colonize with mycorrhiza in the roots (Garg and Cheema, 2021). Plant aquaporins may be affected directly by mycorrhiza, which could stimulate active Si uptake. AM fungi can selectively absorb various elements, including Si, to improve their colonization (Cibils-Stewart et al., 2020). Also, previous research indicated that stressed plants are at a better advantage of becoming hosts for fungal colonization (Zou et al., 2021). Drought acclimation improved external hyphal growth and soil aggregation of mycorrhizal plants (Cheng et al., 2021). As observed in the current study, AMF inoculation enhanced N, P, K, and Si concentration in licorice roots under various water-deficit levels. The ability of mycorrhizal inoculation to alleviate the impacts of drought stress in semiarid areas of the world is demonstrated when plants are observed to have better growth, yield, and nutrient uptake (Bahraminia et al., 2020; Pereira et al., 2021). In the present study, the concentration of Si in licorice roots increased by more than $50 \%$ under inoculated mycorrhizal treatments. This high concentration of Si plays a useful and effective role in drought tolerance. The uptake of $\mathrm{P}$ by plants can be increased by the effect of exogenous Si, according to previous studies on crops (Bhalla and Garg, 2021; Etesami and Jeong, 2021; Vega et al., 
2021). The available literature suggests that having a combination of $\mathrm{Si}$ and microbe treatments can effectively increase plant growth and nutrition. Regardless of the stress conditions, AMF and Si cooperate in key mechanisms to stimulate plant growth. Si synergistically helps plants absorb P efficiently. Si would allow farmers to use organic processes such as mycorrhiza to maintain fertility and improve plant growth instead of artificial P fertilizers (Wang et al., 2022). To enhance plant growth, AMF can be used with the intention of improving plant tolerance to abiotic stresses, while enhancing mineral uptake for establishing optimal concentrations of minerals in plant tissues (especially of P). Also, AMF can improve water relations between the plant and the soil, in addition to the provision of plant protection against soil-borne diseases. AMF can aid plants to obtain macronutrients and micronutrients such as $\mathrm{Cu}, \mathrm{K}, \mathrm{Mg}, \mathrm{N}$, and Zn, especially when they are present in less soluble forms in soils (Vishwakarma et al., 2021). AMF is known to promote nutrient absorption by increasing the absorption area of the roots, as well as by releasing

substances like glomalin which is a glycoprotein that exudes from AMF hyphae and spores (Etesami and Jeong, 2021; Rezakhani et al., 2019). Glomalin in the soil facilitates the uptake of difficult-to-dissolve nutrients like Fe and $\mathrm{P}$. There is a high efficiency with which hyphal surfaces absorb $\mathrm{P}$ from the soil. By comparison, it functions more productively than cylindrical root surfaces and accounts for the higher $\mathrm{P}$ uptake rate where AMF exists (Das et al., 2019).

\section{Conclusion}

The findings of the present study showed that Si application and mycorrhizal inoculation can positively affect morphological and biochemical parameters in licorice, despite various drought stress levels. The protective effects of Si and AMF treatments appear to be connected with the accumulation of secondary metabolites and mineral absorption, thereby improving morphological growth so that licorice production could remain partly unaffected despite water-deficit situations. The present observations showed that $\mathrm{Si}$ and AMF synergistically relieved the effects of drought stress on many features of the plants. Si promoted AMF colonization and the development of fungal structures which, in turn, enhanced Si absorption during mycorrhization. The current findings provide a practical foundation for the use of $\mathrm{Si}$ fertilizers and AMF to better enable licorice production where irrigation systems lean toward a policy of water conservation.

\section{Declarations}

\section{Acknowledgments}

The authors wish to extend their thanks and appreciation to Shiraz University Research and Technology Council as well as Shiraz University of Medical Sciences for their financial supports.

\section{Author contribution}

Tahereh Movahhed Haghighi: Investigation, Methodology, Writing- Original draft preparation, Data analysis; Mohammad Jamal Saharkhiz: Supervision, Validation, Funding acquisition, Reviewing, and 
Editing; Mehdi Zarei: Methodology, Reviewing and Editing.

\section{Conflict of interest}

The authors declare that they have no conflict of interest.

\section{References}

1. Abbaszadeh B, Layeghhaghighi M, Azimi R, Hadi N (2020) Improving water use efficiency through drought stress and using salicylic acid for proper production of Rosmarinus officinalis L. Ind. Crops Prod 144:111893

2. Aboukila EF, Norton JB (2017) Estimation of saturated soil paste salinity from soil-water extracts. Soil Sci 182:107-113

3. Agnolucci M, Avio L, Palla M, Sbrana C, Turrini A, Giovannetti M (2020) Health-Promoting Properties of Plant Products: The Role of Mycorrhizal Fungi and Associated Bacteria. Agronomy 10:1864

4. Alam H, Khattak JZK, Ksiksi TS, Saleem MH, Fahad S, Sohail H, Ali Q, Zamin M, El-Esawi MA, Saud S (2021) Negative impact of long-term exposure of salinity and drought stress on native Tetraena mandavillei L. Physiol Plant 172:1336-1351

5. Alamri S, Hu Y, Mukherjee S, Aftab T, Fahad S, Raza A, Ahmad M, Siddiqui MH (2020) Silicon-induced postponement of leaf senescence is accompanied by modulation of antioxidative defense and ion homeostasis in mustard (Brassica juncea) seedlings exposed to salinity and drought stress. Plant Physiol Biochem 157:47-59

6. Ali M, Afzal S, Parveen A, Kamran M, Javed MR, Abbasi GH, Malik Z, Riaz M, Ahmad S, Chattha MS (2021) Silicon mediated improvement in the growth and ion homeostasis by decreasing $\mathrm{Na}+$ uptake in maize (Zea mays L.) cultivars exposed to salinity stress. Plant Physiol Biochem 158:208-218

7. Arifuzzaman M, Rahman M (2020) Genome wide association mapping and candidate gene mining for root architectural traits in rapeseed/canola (Brassica napus L.) at late growth stage. Euphytica 216:1-21

8. Awan SA, Khan I, Rizwan M, Zhang X, Brestic M, Khan A, El-Sheikh MA, Alyemeni MN, Ali S, Huang L (2021) Exogenous abscisic acid and jasmonic acid restrain polyethylene glycol-induced drought by improving the growth and antioxidative enzyme activities in pearl millet. Physiol Plant 172:809-819

9. Bahraminia M, Zarei M, Ronaghi A, Sepehri M, Etesami H (2020) lonomic and biochemical responses of maize plant (Zea mays L.) inoculated with Funneliformis mosseae to water-deficit stress. Rhizosphere 16:100269

10. Bargrizan S, Smernik RJ, Mosley LM (2017) Development of a spectrophotometric method for determining $\mathrm{pH}$ of soil extracts and comparison with glass electrode measurements. Soil Sci Soc Am J 81:1350-1358

11. Begum N, Akhtar K, Ahanger MA, Iqbal M, Wang P, Mustafa NS, Zhang L (2021) Arbuscular mycorrhizal fungi improve growth, essential oil, secondary metabolism, and yield of tobacco 
(Nicotiana tabacum L.) under drought stress conditions.Environ. Sci. Pollut. Res.1-20

12. Beretta AN, Silbermann AV, Paladino L, Torres D, Kassahun D, Musselli R, Lamohte AG (2014) Soil texture analyses using a hydrometer: modification of the Bouyoucos method. Cienc e Investig Agrar Rev Latinoam ciencias la Agric 41:263-271

13. Bhalla S, Garg N (2021) Arbuscular mycorrhizae and silicon alleviate arsenic toxicity by enhancing soil nutrient availability, starch degradation and productivity in Cajanus cajan (L.) Millsp. Mycorrhiza 31:735-754

14. Boshkovski B, Tzerakis C, Doupis G, Zapolska A, Kalaitzidis C, Koubouris G (2020) Relationships of spectral reflectance with plant tissue mineral elements of common bean (Phaseolus vulgaris $\mathrm{L}$.) under drought and salinity stresses. Commun Soil Sci Plant Anal 51:675-686

15. Bukhari MA, Ahmad Z, Ashraf MY, Afzal M, Nawaz F, Nafees M, Jatoi WN, Malghani NA, Shah AN, Manan A (2020) Silicon mitigates drought stress in wheat (Triticum aestivum L.) through improving photosynthetic pigments, biochemical and yield characters. Silicon 1-16

16. Chakma R, Saekong P, Biswas A, Ullah H, Datta A (2021) Growth, fruit yield, quality, and water productivity of grape tomato as affected by seed priming and soil application of silicon under drought stress. Agric Water Manag 256:107055

17. Cheng H-Q, Giri B, Wu Q-S, Zou Y-N, Kuča K (2021) Arbuscular mycorrhizal fungi mitigate drought stress in citrus by modulating root microenvironment.Arch. Agron. Soil Sci.1-12

18. Cibils-Stewart X, Powell JR, Popay AJ, Lattanzi FA, Hartley SE, Johnson SN (2020) Reciprocal effects of silicon supply and endophytes on silicon accumulation and Epichloë colonization in grasses.Front. Plant Sci.11

19. da Cruz RMS, Alberton O, da Silva Lorencete M, da Cruz GLS, Gasparotto-Junior A, Cardozo-Filho L, de Souza SGH (2020) Phytochemistry of Cymbopogon citratus (DC) Stapf inoculated with arbuscular mycorrhizal fungi and plant growth promoting bacteria. Ind Crops Prod 149:112340

20. Das P, Manna I, Sil P, Bandyopadhyay M, Biswas AK (2019) Exogenous silicon alters organic acid production and enzymatic activity of TCA cycle in two $\mathrm{NaCl}$ stressed indica rice cultivars. Plant Physiol Biochem 136:76-91

21. Dias MC, Pinto DCGA, Figueiredo C, Santos C, Silva AMS (2021) Phenolic and lipophilic metabolite adjustments in Olea europaea (olive) trees during drought stress and recovery. Phytochemistry 185:112695

22. Esmaeili H, Karami A, Hadian J, Saharkhiz MJ, Ebrahimi SN (2019) Variation in the phytochemical contents and antioxidant activity of Glycyrrhiza glabra populations collected in Iran. Ind Crops Prod 137:248-259

23. Etemadi M, Gutjahr C, Couzigou J-M, Zouine M, Lauressergues D, Timmers A, Audran C, Bouzayen M, Bécard G, Combier J-P (2014) Auxin perception is required for arbuscule development in arbuscular mycorrhizal symbiosis. Plant Physiol 166:281-292

24. Etesami H, Jeong BR (2021) Contribution of Arbuscular Mycorrhizal Fungi, Phosphate-Solubilizing Bacteria, and Silicon to P Uptake by Plant: A Review. Front. Plant Sci 12:1355 
25. Garg N, Cheema A (2021) Relative roles of Arbuscular Mycorrhizae in establishing a correlation between soil properties, carbohydrate utilization and yield in Cicer arietinum L. under As stress. Ecotoxicol Environ Saf 207:111196

26. Gavito ME, Jakobsen I, Mikkelsen TN, Mora F (2019) Direct evidence for modulation of photosynthesis by an arbuscular mycorrhiza-induced carbon sink strength. New Phytol 223:896-907

27. Gholami H, Saharkhiz MJ, Fard FR, Ghani A, Nadaf F (2018) Humic acid and vermicompost increased bioactive components, antioxidant activity and herb yield of Chicory (Cichorium intybus L.). Biocatal. Agric Biotechnol 14:286-292

28. Guebel DV, Nudel BC, Giulietti AM (1991) A simple and rapid micro-Kjeldahl method for total nitrogen analysis. Biotechnol Tech 5:427-430

29. Haghighi TM, Saharkhiz MJ (2021) Phytotoxic potential of Vitex pseudo-negundo leaf and flower extracts and analysis of phenolic compounds. Biocatal Agric Biotechnol 34:102018

30. Haghighi TM, Saharkhiz MJ, Kavoosi G, Jowkar A (2022) Monitoring amino acid profile and protein quality of Licorice (Glycyrrhiza glabra L.) under drought stress, silicon nutrition and mycorrhiza inoculation. Sci Hortic (Amsterdam) 295:110808

31. Han Y, Hou Z, Zhang X, Yan K, Liang Z, He Q (2022) Important changes in germination, seedling tolerance, and active components content due to drought stress on three licorice (Glycyrrhiza) species. Ind Crops Prod 175:114240

32. Harikrishnan R, Devi G, Van Doan H, Jawahar S, Balasundaram C, Saravanan K, Arockiaraj J, Soltani $M$, Jaturasitha $S$ (2021) Study on antioxidant potential, immunological response, and inflammatory cytokines induction of glycyrrhizic acid (GA) in silver carp against vibriosis. Fish Shellfish Immunol 119:193-208

33. Harrington JT, Mexal JG, Fisher JT (1994) Volume displacement provides a quick and accurate way to quantify new root production. Seedling 121:124

34. Hazzoumi Z, Moustakime Y, Joutei KA (2015) Effect of arbuscular mycorrhizal fungi (AMF) and water stress on growth, phenolic compounds, glandular hairs, and yield of essential oil in basil (Ocimum gratissimum $\mathrm{L}$ ). Chem Biol Technol Agric 2:1-11

35. Heidari S, Mehri S, Hosseinzadeh H (2021) The genus Glycyrrhiza (Fabaceae family) and its active constituents as protective agents against natural or chemical toxicities. Phyther. Res

36. Hu Y, Xie W, Chen B (2020) Arbuscular mycorrhiza improved drought tolerance of maize seedlings by altering photosystem II efficiency and the levels of key metabolites. Chem Biol Technol Agric 7:1-14

37. Huang G-M, Zou Y-N, Wu Q-S, Xu Y-J, Kuča K (2020) Mycorrhizal roles in plant growth, gas exchange, root morphology, and nutrient uptake of walnuts. Plant Soil Environ 66:295-302

38. Hussain S, Mumtaz M, Manzoor S, Shuxian L, Ahmed I, Skalicky M, Brestic M, Rastogi A, Ulhassan Z, Shafiq I (2021) Foliar application of silicon improves growth of soybean by enhancing carbon metabolism under shading conditions. Plant Physiol Biochem 159:43-52

39. Igiehon ON, Babalola 00 (2021) Rhizobium and Mycorrhizal Fungal Species Improved Soybean Yield Under Drought Stress Conditions. Curr Microbiol 78:1615-1627 
40. Jadhav MVS (2021) Development and Advancement in Image Processing Technique for Detection of Various Diseases in Fruit \&. A Review, Vegetable Plants

41. Jajoo A, Mathur S (2021) Role of arbuscular mycorrhizal fungi as an underground saviuor for protecting plants from abiotic stresses. Physiol. Mol. Biol. Plants 1-15

42. Karkanis A, Martins N, Petropoulos SA, Ferreira ICFR (2018) Phytochemical composition, health effects, and crop management of liquorice (Glycyrrhiza glabra L.): A medicinal plant. Food Rev Int 34:182-203

43. Koentjoro Y, Purwanto E, Purnomo D (2020) Stomatal behaviour of soybean under drought stress with silicon application. Ann Agri Bio Res 25:103-109

44. Kosobryukhov A, Khudyakova A, Kreslavski V (2020) Impact of UV Radiation on Photosynthetic Apparatus: Adaptive and Damaging Mechanisms. Plant Ecophysiol. Adapt. under Clim.Chang. Mech. Perspect. 1555-576

45. Kumar V, Gill KD (2018) To estimate sodium and potassium in serum by using flame photometer. Basic Concepts in Clinical Biochemistry: A Practical Guide. Springer, pp 147-150

46. Lamacque L, Charrier G, Farnese FdosS, Lemaire B, Améglio T, Herbette S (2020) Drought-induced mortality: Branch diameter variation reveals a point of no recovery in lavender species. Plant Physiol 183:1638-1649

47. Lang DY, Fei PX, Cao GY, Jia XX, Li YT, Zhang XH (2019) Silicon promotes seedling growth and alters endogenous IAA, GA3 and ABA concentrations in Glycyrrhiza uralensis under $100 \mathrm{mM} \mathrm{NaCl}$ stress. J Hortic Sci Biotechnol 94:87-93

48. Liang BB, Wang WJ, Fan XX, Kurakov AV, Liu YF, Song FQ, Chang W (2021) Arbuscular mycorrhizal fungi can ameliorate salt stress in Elaeagnus angustifolia by improving leaf photosynthetic function and ultrastructure. Plant Biol 23:232-241

49. Liao X, Chen J, Guan R, Liu J, Sun Q (2021) Two Arbuscular Mycorrhizal Fungi Alleviates Drought Stress and Improves Plant Growth in Cinnamomum migao Seedlings.Mycobiology 1-10

50. Lindsay WL, Norvell WA (1978) Development of a DTPA soil test for zinc, iron, manganese, and copper. Soil Sci Soc Am J 42:421-428

51. Liu A, Ku Y-S, Contador CA, Lam H-M (2020) The impacts of domestication and agricultural practices on legume nutrient acquisition through symbiosis with rhizobia and arbuscular mycorrhizal fungi.Front. Genet.11

52. Liu M, Che Y, Wang L, Zhao Z, Zhang Y, Wei L, Xiao Y (2019) Rice straw biochar and phosphorus inputs have more positive effects on the yield and nutrient uptake of Lolium multiflorum than arbuscular mycorrhizal fungi in acidic Cd-contaminated soils. Chemosphere 235:32-39

53. Ma X, Li X, Ludewig U (2021) Arbuscular mycorrhizal colonization outcompetes root hairs in maize under low phosphorus availability. Ann Bot 127:155-166

54. Majumdar S, Prakash NB (2020) An overview on the potential of silicon in promoting defence against biotic and abiotic stresses in sugarcane.J. Soil Sci. Plant Nutr.1-30 
55. Maurel C, Nacry P (2020) Root architecture and hydraulics converge for acclimation to changing water availability. Nat plants 6:744-749

56. Meimaroglou N, Mouzakis C (2019) Cation Exchange Capacity (CEC), texture, consistency and organic matter in soil assessment for earth construction: The case of earth mortars. Constr Build Mater 221:27-39

57. Miyazawa M, Pavan MA, De Oliveira EL, lonashiro M, Silva AK (2000) Gravimetric determination of soil organic matter. Brazilian Arch Biol Technol 43:475-478

58. Mousavi SS, Karami A (2022) Application of Endophyte Microbes for Production of Secondary Metabolites. Application of Microbes in Environmental and Microbial Biotechnology. Springer, pp 137

59. Mousavi SS, Karami A, Haghighi TM, Alizadeh S, Maggi F (2021) Phytotoxic Potential and Phenolic Profile of Extracts from Scrophularia striata. Plants 10:135

60. Musyoka DM, Njeru EM, Nyamwange MM, Maingi JM (2020) Arbuscular mycorrhizal fungi and Bradyrhizobium co-inoculation enhances nitrogen fixation and growth of green grams (Vigna radiata L.) under water stress. 1036-1047. https://doi.org/10.1080/01904167.2020.1711940. 43

61. Oliveira MLS, Ward CR, Izquierdo M, Sampaio CH, de Brum IAS, Kautzmann RM, Sabedot S, Querol X, Silva LFO (2012) Chemical composition and minerals in pyrite ash of an abandoned sulphuric acid production plant. Sci Total Environ 430:34-47

62. Patel M, Fatnani D, Parida AK (2021) Silicon-induced mitigation of drought stress in peanut genotypes (Arachis hypogaea L.) through ion homeostasis, modulations of antioxidative defense system, and metabolic regulations. Plant Physiol, Biochem

63. Pereira S, Santos M, Leal I, Tabarelli M, Santos MG (2021) Arbuscular mycorrhizal inoculation increases drought tolerance and survival of Cenostigma microphyllum seedlings in a seasonally dry tropical forest. For Ecol Manage 492:119213

64. Pour-Aboughadareh A, Omidi M, Naghavi MR, Etminan A, Mehrabi AA, Poczai P, Bayat H (2019) Effect of water deficit stress on seedling biomass and physio-chemical characteristics in different species of wheat possessing the $D$ genome. Agronomy 9:522

65. Rahimi S, Baninasab B, Talebi M, Gholami M, Zarei M (2021) Arbuscular mycorrhizal fungi inoculation improves iron deficiency in quince via alterations in host root phenolic compounds and expression of genes. Sci Hortic (Amsterdam) 285:110165

66. Ramesha A, Devi DN, Hegde SV, Srinivas C (2020) Biotechnological approaches for the enhancement of anticancer secondary metabolite production from endophytic fungi. New and Future Developments in Microbial Biotechnology and Bioengineering. Elsevier, pp 135-155

67. Rehman MU, Ilahi H, Adnan M, Wahid F, Rehman FU, Raza A (2021) M.A., Application of Silicon: A Useful Way to Mitigate Drought Stress: An Overview

68. Rezakhani L, Motesharezadeh B, Tehrani MM, Etesami H, Hosseini HM (2019) Phosphatesolubilizing bacteria and silicon synergistically augment phosphorus $(P)$ uptake by wheat (Triticum aestivum L.) plant fertilized with soluble or insoluble P source. Ecotoxicol Environ Saf 173:504-513 
69. Riaz U, Kharal MA, Murtaza G, uz Zaman Q, Javaid S, Malik HA, Aziz H, Abbas Z (2019) Prospective roles and mechanisms of caffeic acid in counter plant stress: A mini review. Pakistan J Agric Res $32: 8$

70. Rivero J, Álvarez D, Flors V, Azcón-Aguilar C, Pozo MJ (2018) Root metabolic plasticity underlies functional diversity in mycorrhiza-enhanced stress tolerance in tomato. New Phytol 220:1322-1336

71. Shan C, Zhang S, Ou X (2018) The roles of H 2 S and H 202 in regulating AsA-GSH cycle in the leaves of wheat seedlings under drought stress. Protoplasma 255:1257-1262

72. Shao Y-D, Zhang D-J, Hu X-C, Wu Q-S, Jiang C-J, Gao X-B, Kuča K (2019) Arbuscular mycorrhiza improves leaf food quality of tea plants. Not. Bot. Horti Agrobot, vol 47. Cluj-Napoca, p 3

73. Sharma A, Shahzad B, Rehman A, Bhardwaj R, Landi M, Zheng B (2019) Response of phenylpropanoid pathway and the role of polyphenols in plants under abiotic stress. Molecules $24: 2452$

74. Sharma MP, Grover M, Chourasiya D, Bharti A, Agnihotri R, Maheshwari HS, Pareek A, Buyer JS, Sharma SK, Schütz L (2020) Deciphering the role of trehalose in tripartite symbiosis among rhizobia, arbuscular mycorrhizal fungi, and legumes for enhancing abiotic stress tolerance in crop plants.Front. Microbiol.11

75. Shen Y, Duan Y, McLaughlin N, Huang S, Guo D, Xu M (2019) Phosphorus desorption from calcareous soils with different initial Olsen-P levels and relation to phosphate fractions. J Soils Sediments 19:2997-3007

76. Taban A, Saharkhiz MJ, Kavoosi G (2021) Development of pre-emergence herbicide based on Arabic gum-gelatin, apple pectin and savory essential oil nano-particles: A potential green alternative to metribuzin. Int J Biol Macromol 167:756-765

77. Taban A, Saharkhiz MJ, Khorram M (2020) Formulation and assessment of nano-encapsulated bioherbicides based on biopolymers and essential oil. Ind Crops Prod 149:112348

78. Taban A, Saharkhiz MJ, Niakousari M (2018) Sweet bay (Laurus nobilis L.) essential oil and its chemical composition, antioxidant activity and leaf micromorphology under different extraction methods. Sustain Chem Pharm 9:12-18

79. Tahat MM, Al-Momany AM, IN CUCUMBER TISSUES INFLUENCED BY ENOMYCORRHIZAL FUNGI AND VERTICILLIUM DAHLIAE (2021) PHYTOCHEMICAL CONTENTS. FRESENIUS Environ Bull $30: 4262-4269$

80. Tahmasebi A, Ashrafi-Dehkordi E, Shahriari AG, Mazloomi SM, Ebrahimie E (2019) Integrative metaanalysis of transcriptomic responses to abiotic stress in cotton. Prog Biophys Mol Biol 146:112-122

81. Thakral V, Bhat JA, Kumar N, Myaka B, Sudhakaran S, Patil G, Sonah H, Shivaraj SM, Deshmukh R (2021) Role of silicon under contrasting biotic and abiotic stress conditions provides benefits for climate smart cropping.Environ. Exp. Bot.104545

82. Thorne SJ, Hartley SE, Maathuis FJM (2021) The effect of silicon on osmotic and drought stress tolerance in wheat landraces. Plants 10:814 
83. Tripathi P, Na C-I, Kim Y (2021) Effect of silicon fertilizer treatment on nodule formation and yield in soybean (Glycine max L.). Eur J Agron 122:126172

84. Trouvelot A, Kough JL, Gianinazzi-Pearson V (1986) Estimation of vesicular arbuscular mycorrhizal infection levels. Research for methods having a functional significance, in: Physiological and Genetical Aspects of Mycorrhizae= Aspects Physiologiques et Genetiques Des Mycorhizes: Proceedings of the 1st European Symposium on Mycorrhizae, Dijon, 1-5 July 1985. Paris: Institut national de le recherche agronomique, c1986

85. Vega I, Pontigo S, Nunes-Nesi A, de la Luz Mora M, Meier S, Cartes P (2021) Interaction Between Silicon and Arbuscular Mycorrhizal Symbiosis: an Ecologically Sustainable Tool to Improve Crop Fitness Under a Drought Scenario?J. Soil Sci. Plant Nutr.1-14

86. Verma A, Mudila H, Prasher P, Verma S (2021) Flavonoid Infochemicals: Unravelling Insights of Rhizomicrobiome Interactions, in: Microbial Metatranscriptomics Belowground. Springer, pp 163177

87. Vishwakarma K, Kumar N, Shandilya C, Varma A (2021) Unravelling the role of endophytes in micronutrient uptake and enhanced crop productivity. Symbiotic Soil Microorganisms. Springer, pp 63-85

88. Wang L, Yang D, Ma F, Wang G, You Y (2022) Recent advances in responses of arbuscular mycorrhizal fungi-Plant symbiosis to engineered nanoparticles. Chemosphere 286:131644

89. Wang M, Wang R, Mur LAJ, Ruan J, Shen Q, Guo S (2021) Functions of silicon in plant drought stress responses. Hortic Res 8:1-13

90. Wang Q, Sheng J, Wang Y, Chen K, Lambers H, Wang X (2021) The relative contribution of indigenous and introduced arbuscular mycorrhizal fungi and rhizobia to plant nutrient acquisition in soybean/maize intercropping in unsterilized soils. Appl Soil Ecol 168:104124

91. Wen-Ya MA, Qiang-Sheng WU, Yong-Jie XU, Kamil K (2021) Exploring mycorrhizal fungi in walnut with a focus on physiological roles. Not Bot Horti Agrobot Cluj-Napoca 49:12363

92. Xiao S, Liu L, Zhang Y, Sun H, Zhang K, Bai Z, Dong H, Li C (2020) Fine root and root hair morphology of cotton under drought stress revealed with RhizoPot. J Agron Crop Sci 206:679-693

93. Zahedi SM, Karimi M, Venditti A (2019) Plants adapted to arid areas: specialized metabolites.Nat. Prod. Res.1-18

94. Zarei M, Abadi VAJM, Silva JAT, da (2020) Potential of arbuscular mycorrhizae and tall fescue in remediation of soils polluted with zinc. https://doi.org/10.1080/02757540.2019.1705285 36, 122137. https://doi.org/10.1080/02757540.2019.1705285

95. Zhang W, Xie Z, Wang L, Li M, Lang D, Zhang X (2017) Silicon alleviates salt and drought stress of Glycyrrhiza uralensis seedling by altering antioxidant metabolism and osmotic adjustment. J Plant Res 130:611-624

96. Zhang WJ, Zhang XJ, Lang DY, Li M, Liu H, Zhang XH (2020) Silicon alleviates salt and drought stress of Glycyrrhiza uralensis plants by improving photosynthesis and water status. Biol Plant 64:302-313 
97. Zou Y, Wu Q, Kuča K (2021) Unravelling the role of arbuscular mycorrhizal fungi in mitigating the oxidative burst of plants under drought stress. Plant Biol 23:50-57

Figures
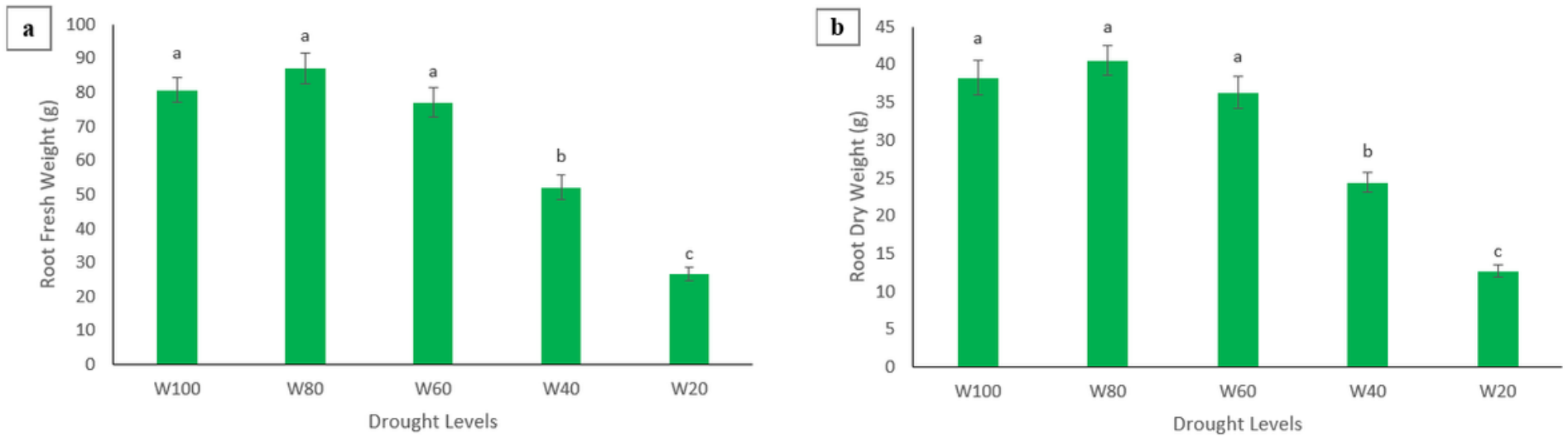

\section{Figure 1}

Root biomass variation. (a) Root fresh weight variation and (b) root dry weight variation among various drought stress levels in examined Licorice plants. According to the analysis of variance that only the main effect of drought levels showed a significant difference, just its mean comparison is shown. Mean values with the same letters are not significantly different $(p<0.05)$, Tukey test.

Abbreviations: W stands for water deficit treatment (5 levels including 100\% $\left(\mathrm{W}_{100}\right), 80 \%\left(\mathrm{~W}_{80}\right), 60 \%$ $\left(\mathrm{W}_{60}\right), 40 \%\left(\mathrm{~W}_{40}\right)$ and $20 \%\left(\mathrm{~W}_{20}\right)$ of field capacity).
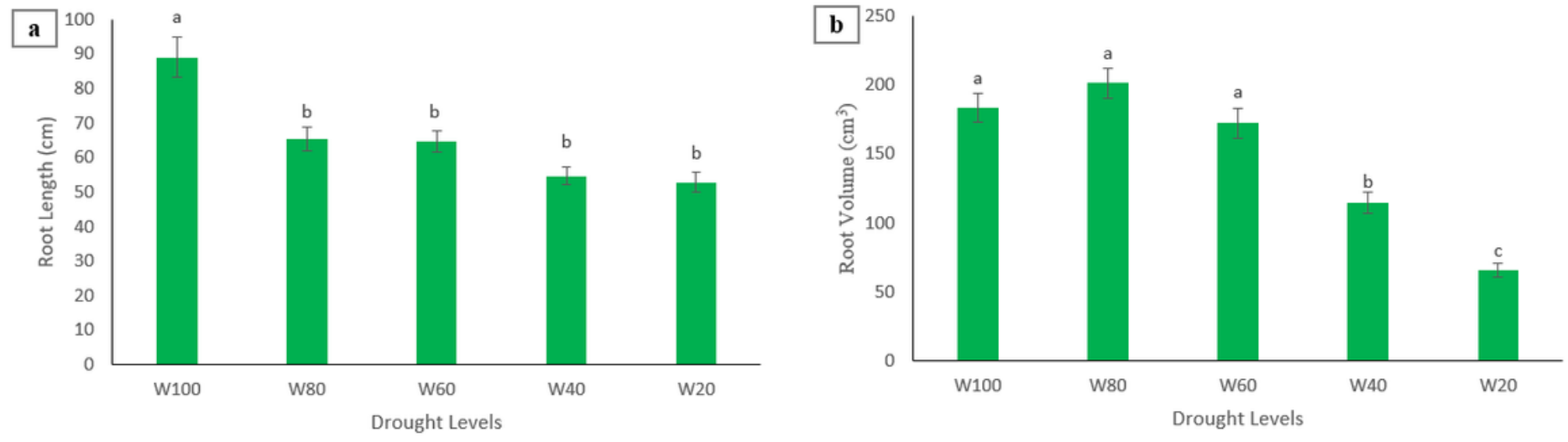

Figure 2

Root traits variation. (a) Root length variation and (b) root volume variation among various drought stress levels in examined Licorice plants. According to the analysis of variance that only the main effect of 
drought levels showed a significant difference, just its mean comparison is shown. Mean values with the same letters are not significantly different $(p<0.05)$, Tukey test.

Abbreviations: $W$ stands for water deficit treatment (5 levels including 100\% $\left(\mathrm{W}_{100}\right), 80 \%\left(\mathrm{~W}_{80}\right), 60 \%$ $\left(\mathrm{W}_{60}\right), 40 \%\left(\mathrm{~W}_{40}\right)$ and $20 \%\left(\mathrm{~W}_{20}\right)$ of field capacity).

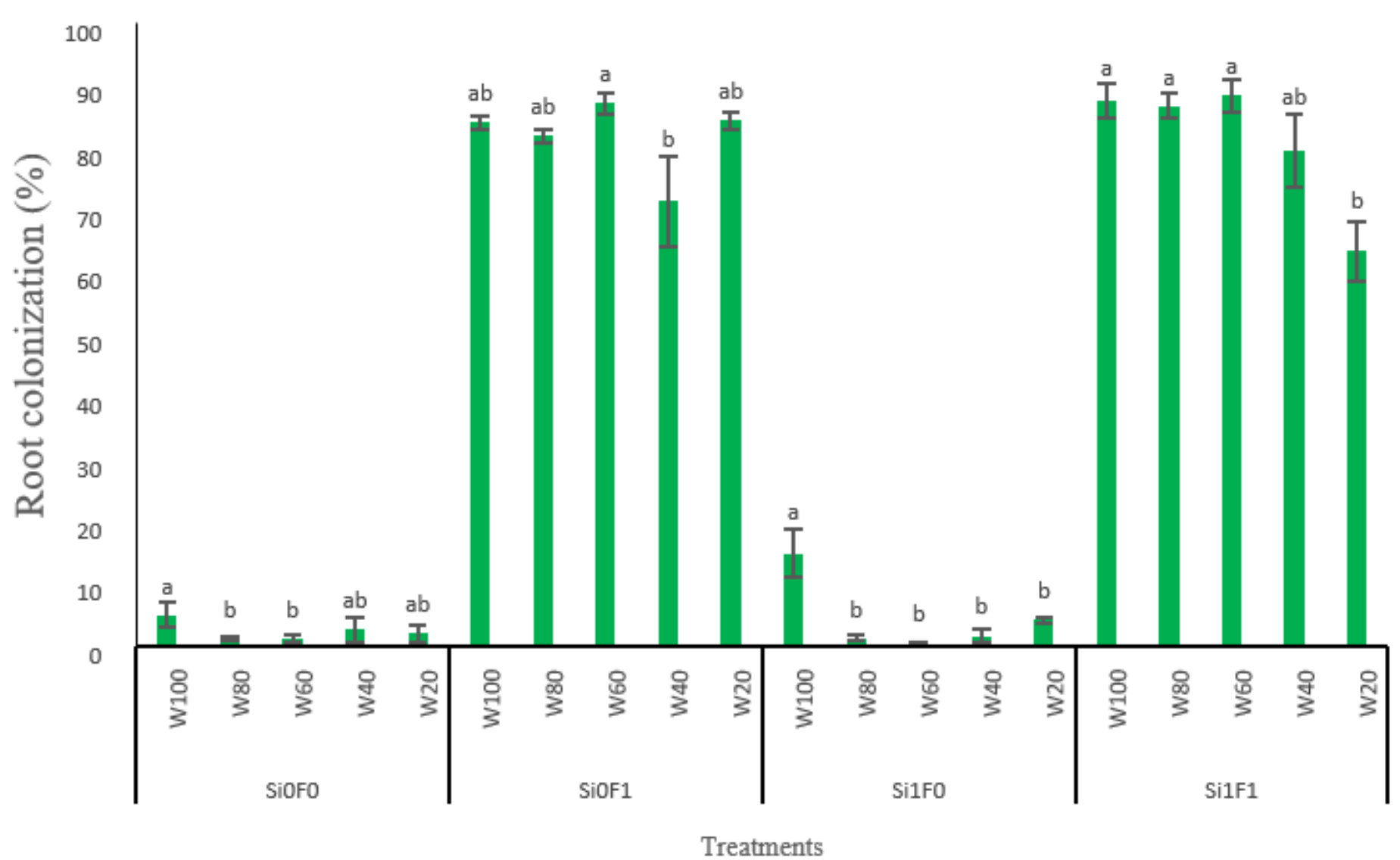

Figure 3

Root colonization variation among drought stress, Si application, and mycorrhiza inoculation interactions in examined Licorice plants. According to the analysis of variance that triple effects of fungi, drought levels, and Si showed a significant difference, the slice method was used for mean comparisons. Mean values with the same letters are not significantly different $(p<0.05)$, Tukey test.

Abbreviations: $W$ stands for water deficit treatment (5 levels including 100\% $\left(\mathrm{W}_{100}\right), 80 \%\left(\mathrm{~W}_{80}\right), 60 \%$ $\left(\mathrm{W}_{60}\right), 40 \%\left(\mathrm{~W}_{40}\right)$, and $20 \%\left(\mathrm{~W}_{20}\right)$ of field capacity), Si stands for silicon application (two levels including $\mathrm{Si}_{0}$ (no $\mathrm{Si}$ application) and $\mathrm{Si}_{1}$ (Si application)) and $\mathrm{F}$ stands for mycorrhiza inoculation (two levels including $\mathrm{F}_{0}$ (no inoculation) and $\mathrm{F}_{1}$ (inoculated)). 


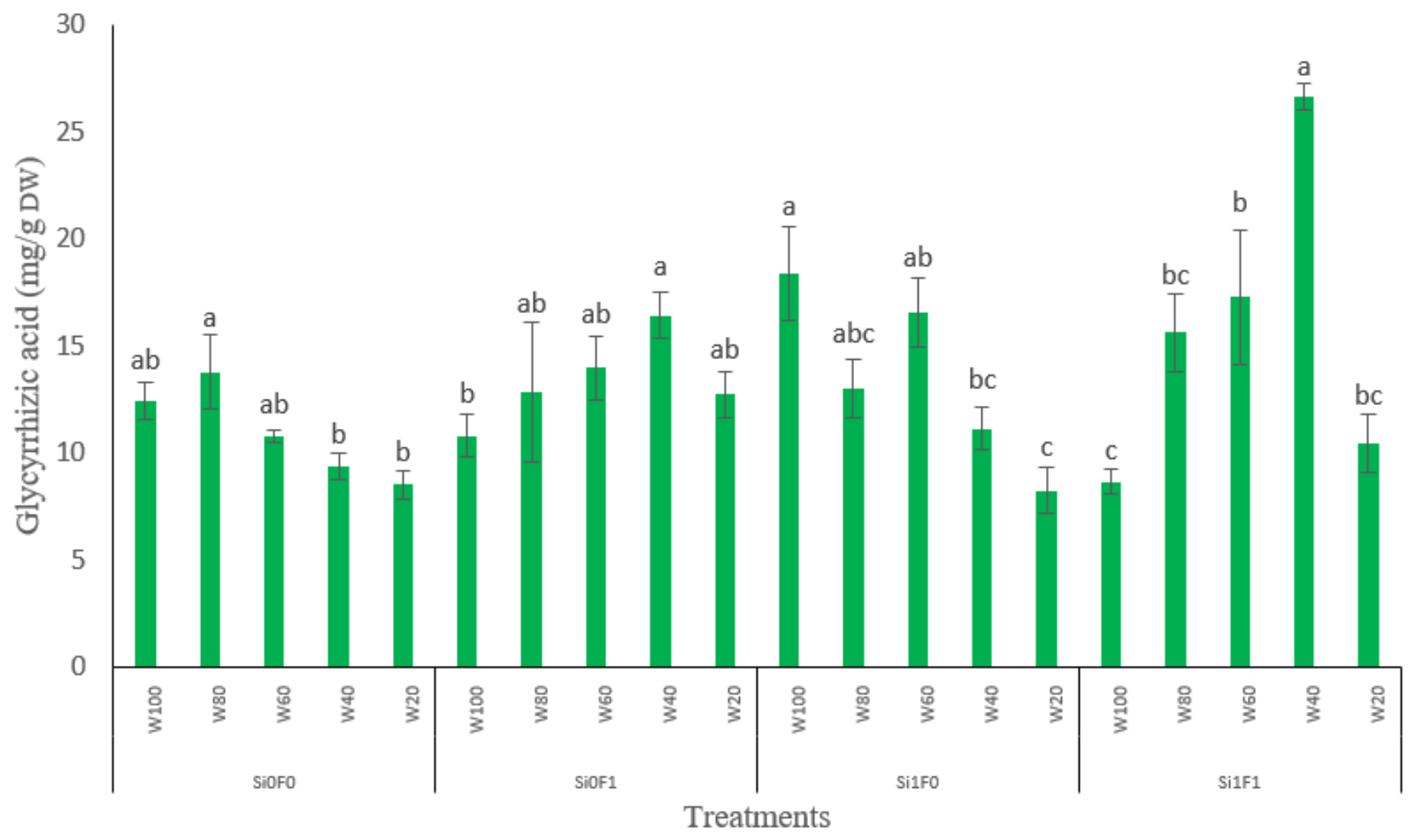

Figure 4

Glycyrrhizic acid content variation among drought stress, Si application, and mycorrhiza inoculation interactions in examined Licorice plants. According to the analysis of variance that triple effects of fungi, drought levels, and Si showed a significant difference, the slice method was used for mean comparisons. Mean values with the same letters are not significantly different in each treatment $(p<0.05)$, Tukey test.

Abbreviations: $W$ stands for water deficit treatment (5 levels including 100\% $\left(\mathrm{W}_{100}\right), 80 \%\left(\mathrm{~W}_{80}\right), 60 \%$ $\left(\mathrm{W}_{60}\right), 40 \%\left(\mathrm{~W}_{40}\right)$, and $20 \%\left(\mathrm{~W}_{20}\right)$ of field capacity), Si stands for silicon application (two levels including $\mathrm{Si}_{0}$ (no $\mathrm{Si}$ application) and $\mathrm{Si}_{1}$ (Si application)) and $\mathrm{F}$ stands for mycorrhiza inoculation (two levels including $F_{0}$ (no inoculation) and $F_{1}$ (inoculated)). 

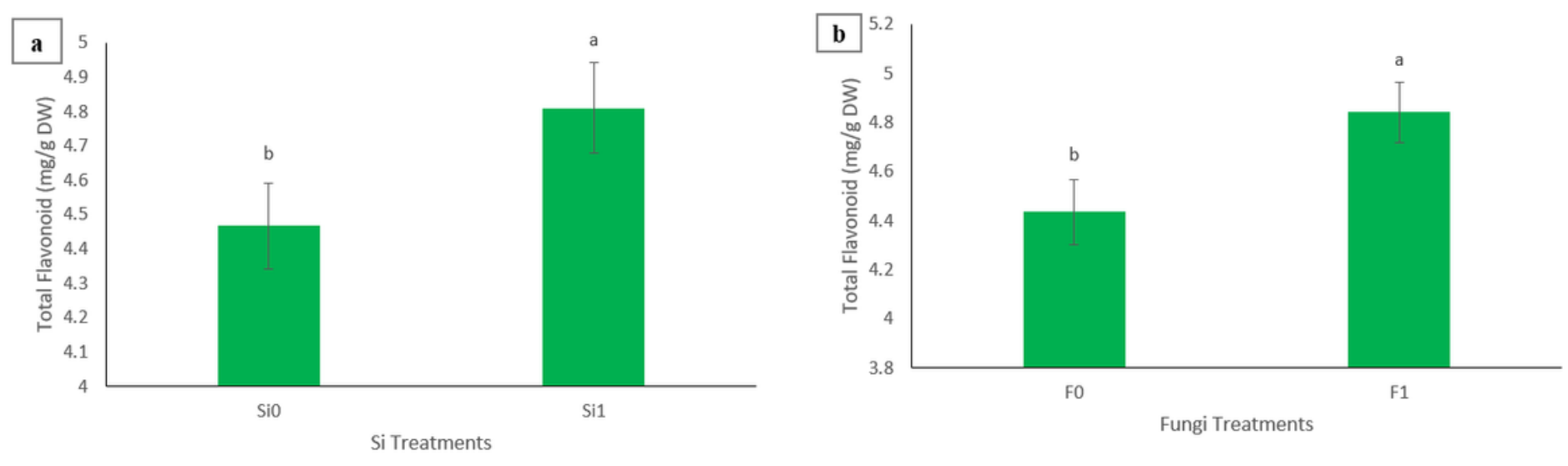

Figure 5

(a) Total flavonoid content variation among two Si levels in examined Licorice plants. (b) Total flavonoid content variation among two mycorrhiza inoculation levels in examined Licorice plants. According to the analysis of variance, only the main effects of fungi and Si showed a significant difference, just those mean comparisons are shown. Mean values with the same letters are not significantly different $(p<0.05)$, Tukey test.

Abbreviations: Si stands for silicon application (two levels including $\mathrm{Si}_{0}$ (no Si application) and $\mathrm{Si}_{1}(\mathrm{Si}$ application)) and $F$ stands for mycorrhiza inoculation (two levels including $F_{0}$ (no inoculation) and $F_{1}$ (inoculated)). 


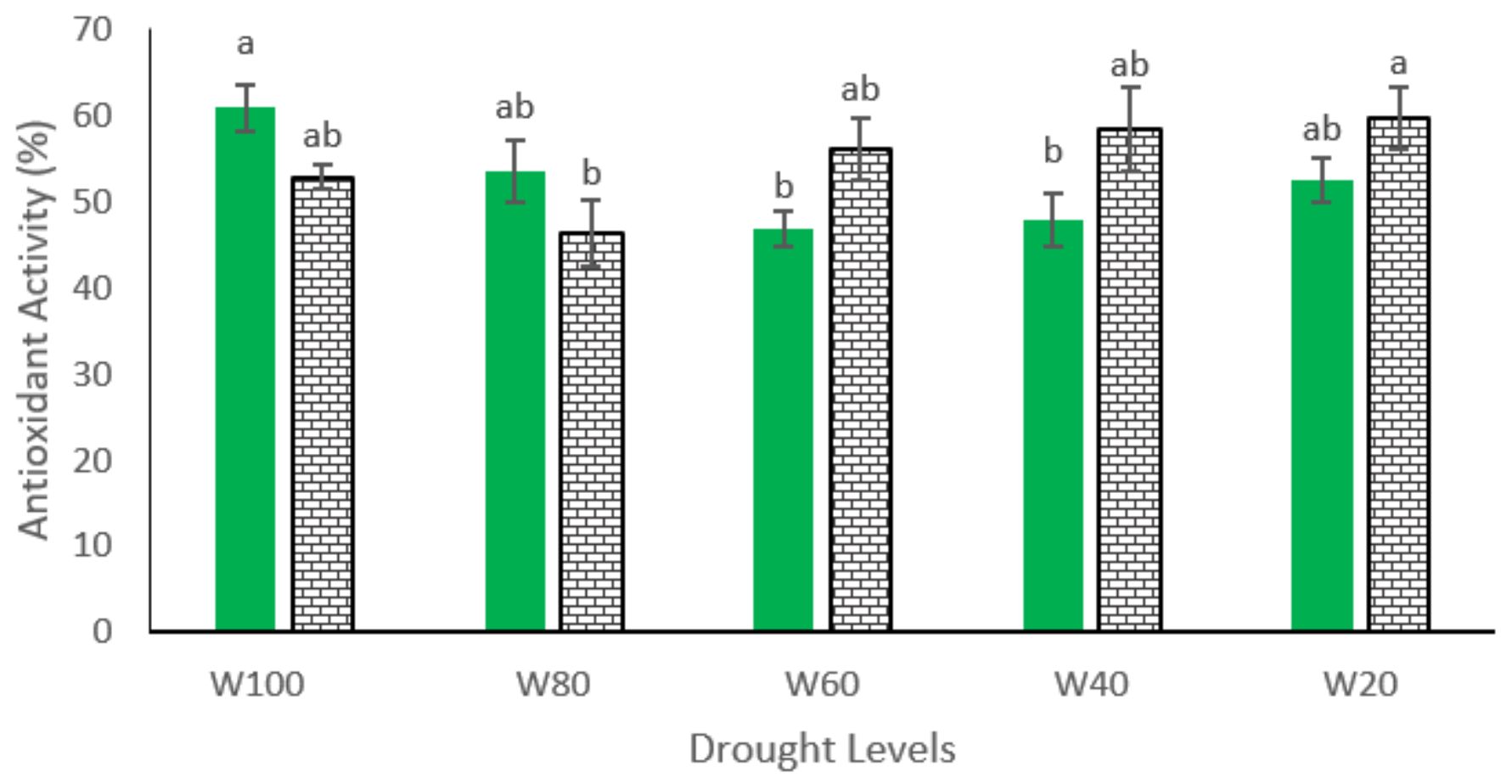

Figure 6

Antioxidant activity variation among various drought stress and mycorrhiza inoculation levels in examined Licorice plants. According to the analysis of variance that only the multiple effects of fungi and drought levels showed a significant difference, just its mean comparison is shown. Mean values with the same letters are not significantly different $(p<0.05)$, Tukey test.

Abbreviations: $W$ stands for water deficit treatment (5 levels including 100\% $\left(\mathrm{W}_{100}\right), 80 \%\left(\mathrm{~W}_{80}\right), 60 \%$ $\left(\mathrm{W}_{60}\right), 40 \%\left(\mathrm{~W}_{40}\right)$ and $20 \%\left(\mathrm{~W}_{20}\right)$ of field capacity) and $\mathrm{F}$ stands for mycorrhiza inoculation (two levels including $\mathrm{F}_{0}$ (no inoculation) and $\mathrm{F}_{1}$ (inoculated)). 


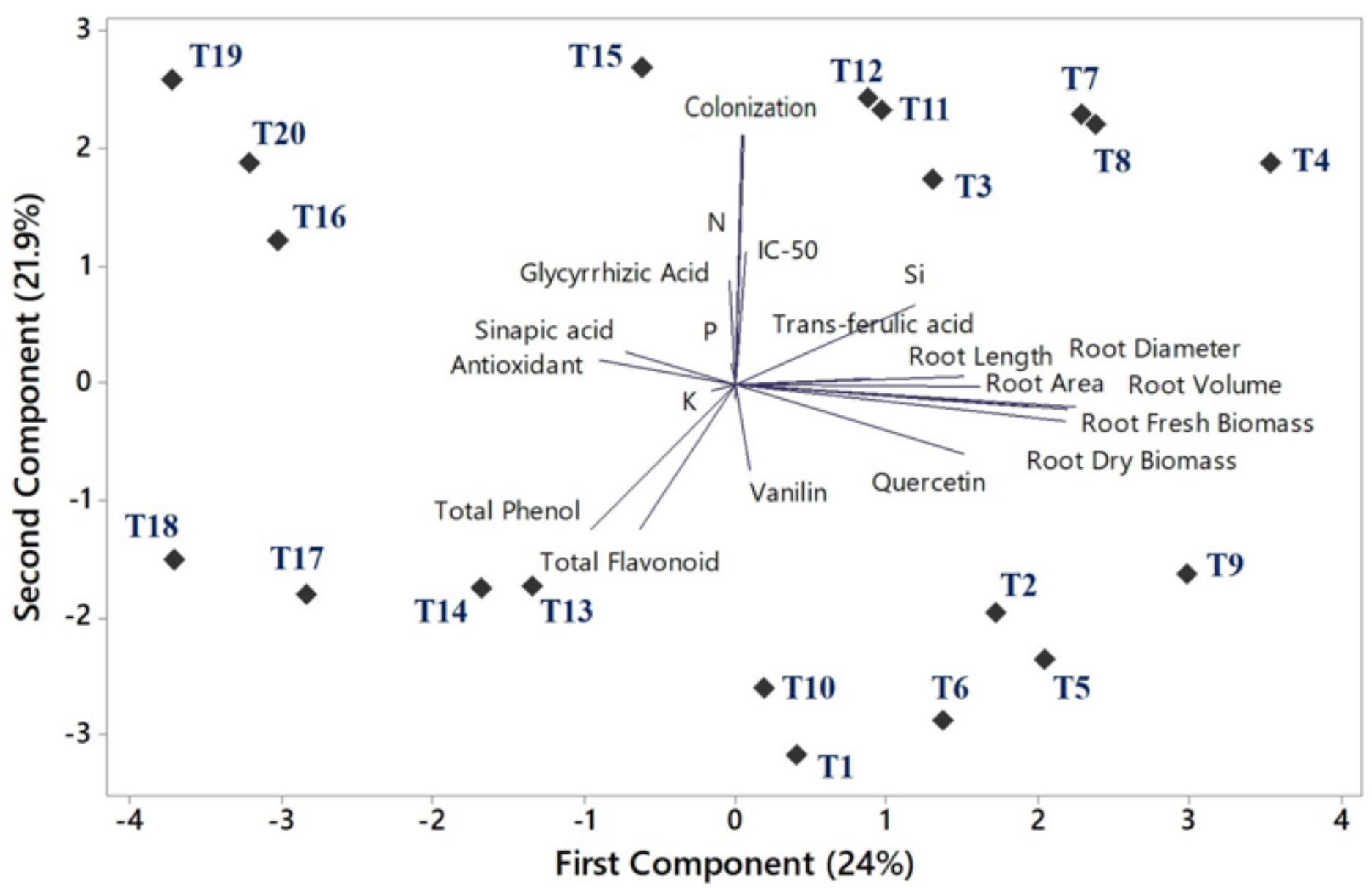

Figure 7

Principal component analysis of studied treatments on various measured parameters

of licorice. Abbreviations: Treatments $(T)$ are shown with numbers; $1: W_{100} S i_{0} F_{0} ; 2: W_{100} S i_{1} F_{0} ; 3: W_{100}$ $S_{0} F_{1} ; 4: W_{100} S i_{1} F_{1} ; 5: W_{80} S i_{0} F_{0} ; 6: W_{80} S i_{1} F_{0} ; 7: W_{80} S i_{0} F_{1} ; 8: W_{80} S i_{1} F_{1} ; 9: W_{60} S i_{0} F_{0} ; 10: W_{60} S i_{1} F_{0} ;$ 11: $W_{60} S i_{0} F_{1} ; 12: W_{60} S i_{1} F_{1} ; 13: W_{40} S i_{0} F_{0} ; 14: W_{40} S i_{1} F_{0} ; 15: W_{40} S i_{0} F_{1} ; 16: W_{40} S i_{1} F_{1} ; 17: W_{20} S i_{0} F_{0} ;$ 18: $W_{20} \mathrm{Si}_{1} \mathrm{~F}_{0} ; 19: \mathrm{W}_{20} \mathrm{Si}_{0} \mathrm{~F}_{1} ; 20: \mathrm{W}_{20} \mathrm{Si}_{1} \mathrm{~F}_{1}$.

\section{Supplementary Files}

This is a list of supplementary files associated with this preprint. Click to download.

- Supplementarymetabolite.docx 